\title{
Threats to Smart Solid waste Management in Sudan
}

\author{
Abu Bakr El Siddig Ahmed El Tohami* \\ Associate Professor of Environmental Management and Impact Assessment, Faculty of Environmental Sciences Omdurman Ahlia University, Sudan
}

Received: 阱 August 08, 2018; Published: 阱 August 16, 2018

*Corresponding author: Abu Bakr El Siddig Ahmed El Tohami, Associate Professor of Environmental Management and Impact Assessment, Faculty of Environmental Sciences Omdurman Ahlia University, Sudan

\begin{abstract}
This paper is an attempt to highlight the factors that threaten the smartness of solid waste management in Sudan with an emphasis urban area in the country as well as it is trail to draw a road map to attain what is called Smart solid waste management. This paper is a review article and it depends on the personal experience of the author. Non-smart solid waste management can be attributed to the following factors: vast horizontal expansion of settlements both formal and informal types accompanied by increase in the population of urban centers (in general and Khartoum state in particular) due to pushing and pulling factors. Pulling factors are deterioration in essential infrastructure and communities' services in rural areas such as health and education facilities, poor or absence of rural development. Other pushing factors are tribal conflicts and violence due to natural factors such as drought and desertification and struggle over the scarce natural resources which enhanced rural- urban migration. This horizontal expansion of the settlements and continuous increase in population have resulted in increase of the generated solid wastes, inefficient means of solid waste management, insufficient number of vehicles, poor salaries of the labor working in collection and transportation and segregation of solid wastes.

This were reflected in the accumulation and scattering of solid wastes which ultimately led to non-smartness of management of such wastes. The following recommendations can be drawn: Rehabilitation of large irrigated schemes in Sudan such as Gezira and Rahad schemes which will improve the balance of payment, ensuring food security and living conditions in rural areas, To treat the actual or root causes of rapid expansion in Khartoum State by strengthening essential infrastructure in rural areas as education and health services, Construction of high buildings rather than flat will reduce the travelling distances and running costs of vehicles working in collection, Attraction of the private sector to invest in recycling and reuse the wastes, Raising the environmental awareness through media and educational institutes
\end{abstract}

Keywords: Horizontal expansion; Smart solid wastes management; Pulling and pushing factors

\section{Introduction}

Waste management includes all the activities and actions required to manage waste from its starting to its final disposal. This also includes other things, collection, transport, treatment and disposal of waste together with proper monitoring and regulation. It encompasses the legal and regulatory framework that related to waste management guidance on recycling etc. The term waste management usually relates to all kinds of waste, whether generated during the extract ion of raw materials, the processing of raw materials into final products, the consumption of final products, or other human activities, including municipal, agricultural, and social like health care etc. Waste management is introduced to reduce the effects of waste on health, the environment or aesthetics. We are providing a digital approach to waste management which provides smart and effective impact on Waste Management [1].

Solid waste management is one of the most important challenges throughout the world and it has become a critical issue in developing countries where a rapid increase in population has been observed. Waste collection is a complex process that requires the use of large amount of money and an elaborate management of logistics. Every city can become smarter. Smart cities start with smart systems that work for the benefit of both residents and the environment. The cities that succeed in making the transition to 'smart' will be those that improve their critical systems by combining a bottom-up, systems-centric approach with a topdown, data-centric one. It is the improvement and integration of various critical city systems - done in a step-by-step manner - that become the cornerstones to making a smart city a reality. To attract the most promising residents, companies, and organizations, as well as promote a thriving culture, cities must achieve three critical traits: become more efficient, more livable, and more sustainable.

By the end of the current decade, many technologies critical to a smart city, including monitoring and sensor technologies, intelligent traffic systems, and energy management systems for buildings, will be deployed on every continent. While the challenges are many, the benefits are significant. Going beyond the obvious environmental benefits, the improvement of systems can contribute to social equality through universal access to a city's public services. They 
save lives by allowing for more immediate access to emergency services. They make cities more resilient in times of crisis, allow cities to prepare for hazards, and help to restore city services from disruption in the wake of one [2].

\section{Background to the Problem of Inefficient (i.e. Non- Smart) Solid Waste Management}

Solid waste management practices throughout Sudan are uniformly poor. Management is limited to organized collection from the more affluent urban areas and dumping in open landfills or open ground. In the majority of cases, garbage of all types accumulates close to its point of origin and is periodically burnt. Litter - plastic bags in particular - is a pervasive problem across the country, with Khartoum state being worst affected due to its population density and relative wealth [3]. UNEP field teams visited a number of municipal dumpsites in Port Sudan, Khartoum, El Obeid, El Geneina, Wau, Juba, Malakal and Bor, as well as in smaller towns and villages. Of all of the sites visited, only Khartoum and Juba were found to have organized systems of dumping waste into predefined moderately suitable locations. In all other cases, dumping took place on the outskirts of urban centers. Moreover, there was no waste separation at source, and slaughterhouse offal, medical wastes, sewage and chemicals were seen within the normal waste stream. Waste was also commonly dumped directly into seasonal watercourses or rivers, thereby contributing to water pollution and waterborne diseases. Carefully designed water points, such as this one that is connected to a deep well in Western Darfur, can help control the spread of waterborne diseases Wind-blown litter is an endemic problem in the countryside around major towns in northern and central Sudan Open air burning is the most common method of waste disposal in IDP settlements such as this one on the southern fringe of Khartoum [3].

\section{Objectives}

This article aims at identifying factors that threaten smart solid waste management in Sudan as well as to draw a road map that enable the country to attain this smartness.

\section{Materials and Methods}

\section{Materials}

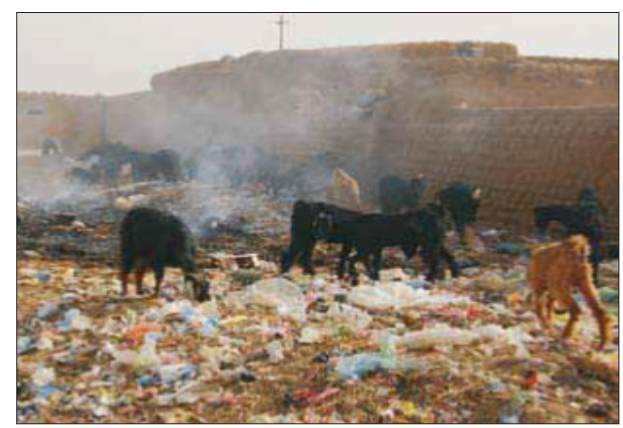

Figure 1: Open air burning is the most common method of waste disposal in IDP settlements such as this one on the southern fringe of Khartoum.
The conceptualization of Smart City, therefore, varies from city to city and country to country, depending on the level of development, willingness to change and reform, resources and aspirations of the city residents. A smart city would have a different connotation in India than, say, Europe. es that drive growth and prosperity. In this paper an approach to smart waste collection is proposed able to improve and optimize the handling of solid waste [2]. "Smart city" is one such use went for upgrading the lifestyle of individuals. One of the real obstacles in numerous urban groups is its strong waste administration, and compelling administration of the strong waste created transforms into a principal part of a savvy city [4] (Figures $1 \& 2$ ).

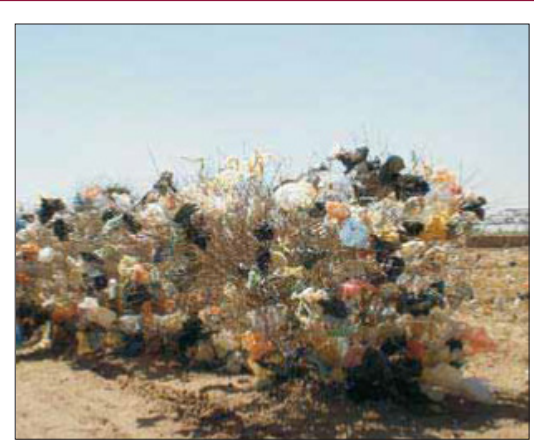

Figure 2: Wind-blown litter is an endemic problem in the countryside around major towns in northern and central Sudan.

\section{Methods}

This article is based on reviewing the relelevant literature and the personal experience of the author.

\section{Results and Discussion}

\section{Threats to Smart Solid Waste Management}

Solid waste management in Sudan is far from being smart due to number of factors. Some of these factors are administrative, managerial and financial in origin while others due to the deterioration of natural environments in rural areas i.e. these problems originate from the rural areas rather than the urban areas. Inefficient soiled waste management in urban areas of Sudan in general and Khartoum State in particular can be summed up as follows $[5,6]$.

a) Horizontal expansion of Khartoum state: The total area of this state is more $22000 \mathrm{~km} 2$. Unfortunately, the authority has failed to stop illegal expansion of settlements regardless of efforts and different plans done to legalize the illegal expansion. However, these plans encourage new comers to develop new slims. This vast expansion of urban settlements in fact beyond the capacity of the Solid waste management authority and the foreign companies working in management.

b) Wide spread of formal informal settlements which lack the essential community and health services such as regular collection of solid wastes and potable water etc. Moreover such types of settlements are locating in remote areas which lie far away from the central stations and landfills; 
c) The available number of vehicles is far below the actual needs for collection and transportation of wastes to the central stations or landfills i.e. number of vehicles is incompatible with growing needs of the local citizens;

d) Lack of regular maintenance or workshops for the vehicles working in collection, transportation and dumping of these wastes;

e) Insufficient budgets to purchase new vehicles or provision of the required spare parts that ensure the sustainability in these processes;

f) Poor salaries for labors working in waste management;

g) Insufficient number of labor due to the above-mentioned cause which is poor salaries does not attract new labor and discourage people to work in such a job;

h) Poor environmental perception (awareness) and/ or irrational environmental behaviour for people who are already aware with negative impacts of inefficient solid waste management

\section{Road Map for Smart Waste Management in Sudan}

a) To treat the actual or root causes of rapid expansion in Khartoum State by strengthening essential infrastructure in rural areas as education and health services and every person in the society should have access to natural resources, educating and training the rural people;

b) Rehabilitation of large irrigated schemes in Sudan such as Gezira and Rahad schemes which will improve the balance of payment, ensuring food security and living conditions in rural areas. This will definitely help in attracting the young people who left their villages to Khartoum state and working on marginal job. of course, these will reduce the population in Khartoum state and consequently will improve solid waste management systems;

ISSN: 2574-1241

DOI: 10.26717/BJSTR.2018.08.001595

Abu Bakr El Siddig Ahmed El T. Biomed J Sci \& Tech Res

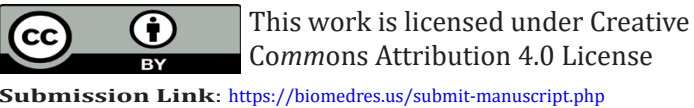

c) Construction of high buildings rather than flat will reduce the travelling distances and running costs of vehicles working in collection and transportation of solid wastes to the final dumping sites;

d) Attraction of the private sector to invest in recycling and reuse the wastes which can generate foreign currencies and provide more job opportunities and improving the standard of living of the all citizens.

e) Recycling helps in reducing the immense or huge quantities of solid wastes as well as the running costs used in solid waste management without or with little success; and

f) Raising the environmental awareness through media and educational institutes aiming at enabling them to be friendly with urban environment in which they are living.

\section{References}

1. SPatil S, Rashmi SZ, Rathod PP, Babanne V (2017) Smart City Waste Management, International Journal of Engineering Science and Computing, India, 7(1).

2. Hassan SA, Noor Ghazi M, Jameel SA, NG Şekeroğlu B (2016) Smart Solid Waste Monitoring and Collection System, International Journal of Advanced Research in Computer Science and Software Engineering, $6(10)$.

3. UNEP (2007) Sudan Post Conflict, Environmental Assessment, Nairobi, Kenya.

4. Vaisali G, Bhargavi KS, Kumar S (2017) Smart Solid Waste Management System by internet of Thing (IOT), International Journal of Mechanical Engineering and Technology (IJMET) 8(12): 841-846,

5. El Tohami AEA (2013) Towards a sustainable livelihood in Sudanese Cities, African Journal of Environmental Philosophy. University of Lagos Nigeria Volume II.

6. Personal Experience of the Author.

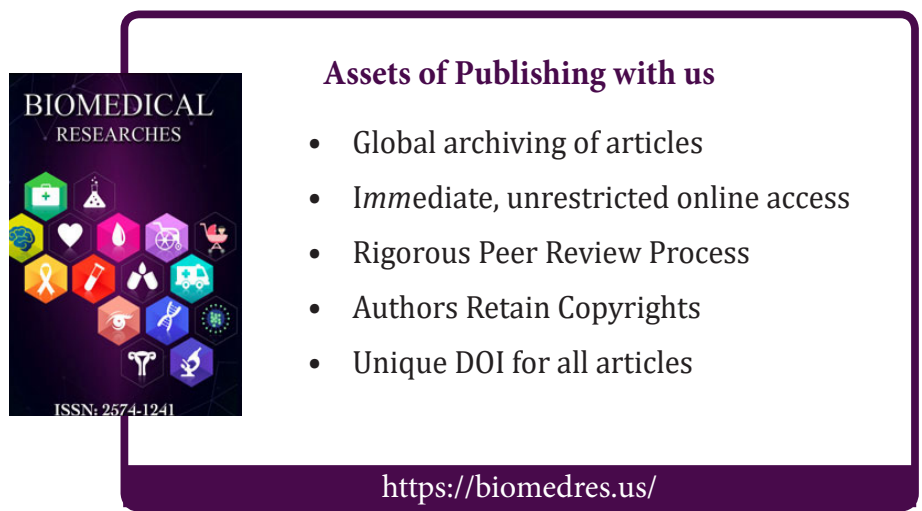

